\title{
Notes on the vocalizations of Rufous-breasted Leaftosser (Sclerurus scansor)
}

Peter Boesman

In the following we briefly analyze and compare voice of the two races of Rufous-breasted Leaftosser (Sclerurus scansor). We also try to quantify the extent of any vocal differences using the criteria proposed by Tobias et al. (2010), as a support for taxonomic review. We have made use of sound recordings available on-line from Xeno Canto (XC) and Macaulay Library (ML).

Voice in general of both races is quite variable, but nevertheless race cearensis seems to show some consistent differences vs. nominate. In the following we compare some main vocalizations, illustrated by a sonogram:

scansor

Song typically is a fast rattle decreasing in pitch towards the end and slowing down somewhat:

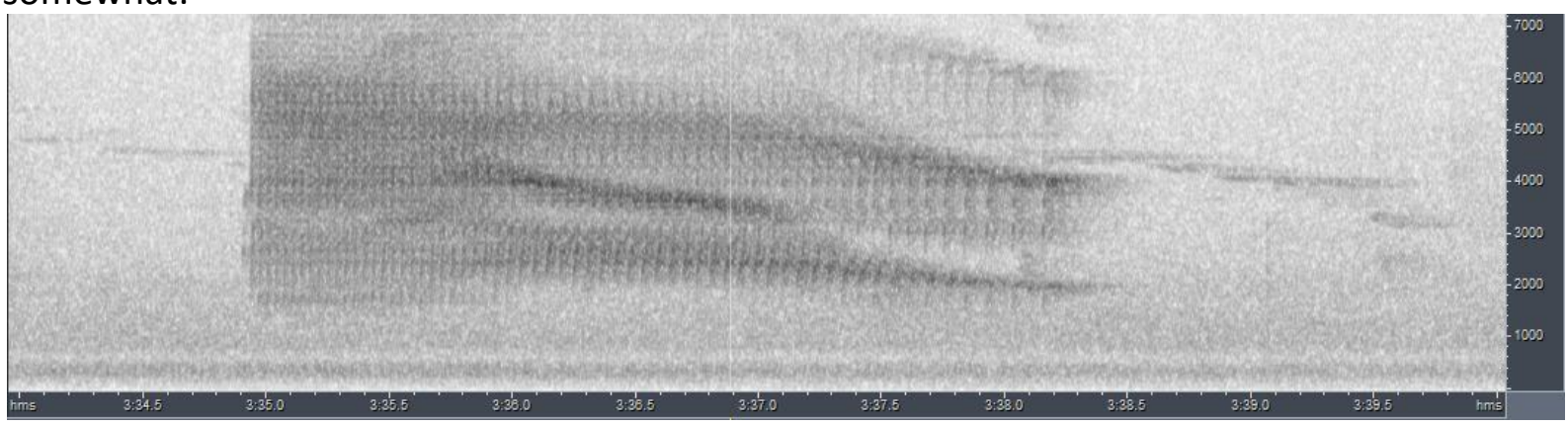

When excited, the descending rattle is preceded by a series of fast underslurred notes rising in pitch:

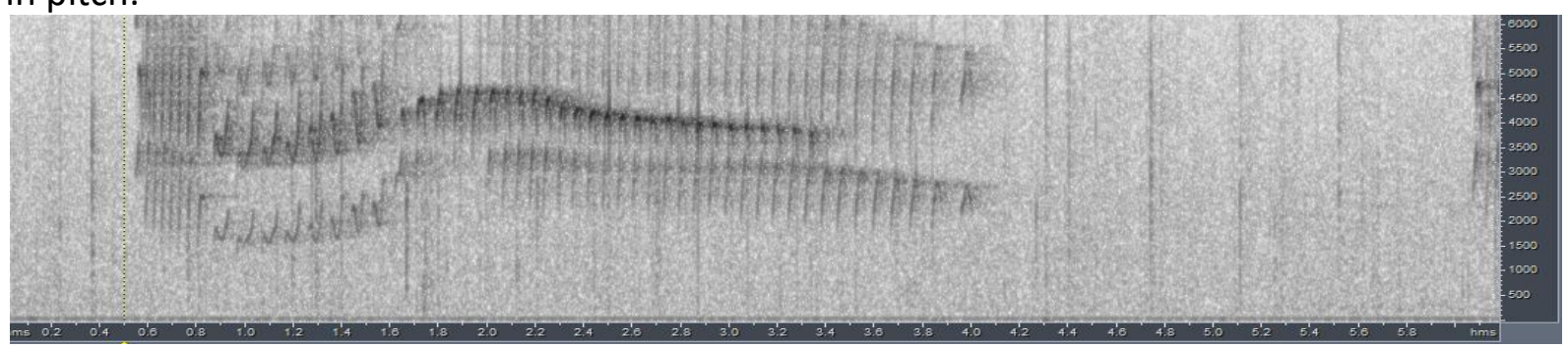

What could be called 'long call' or 'short song' is a descending series of notes:

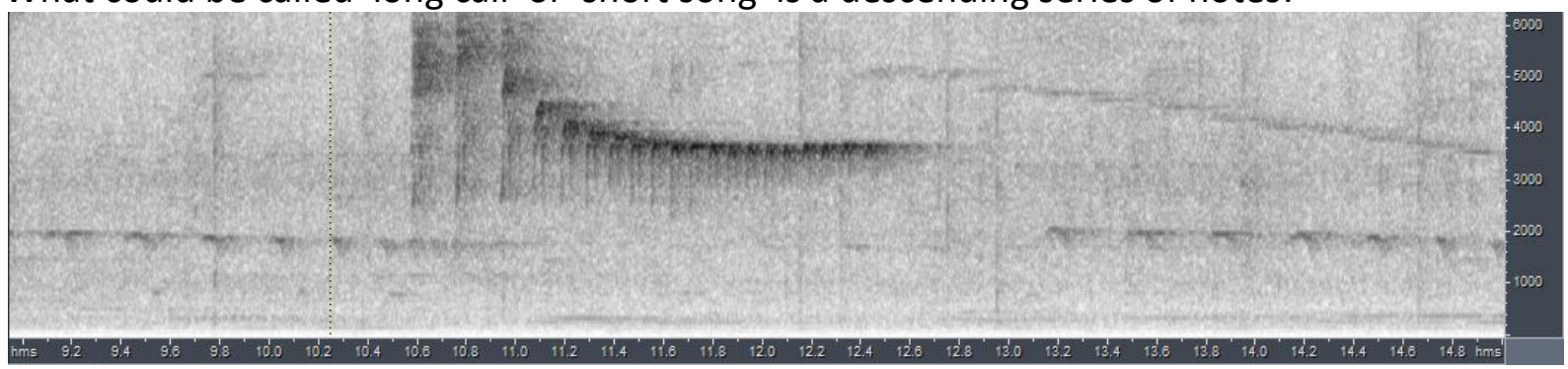




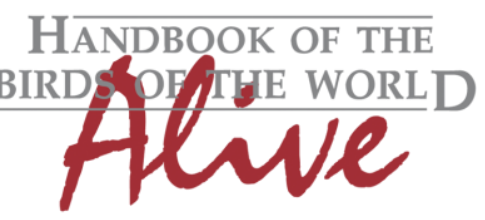

\section{ORNITHOLOGICAL NOTES}

Call is a sharp, short note:

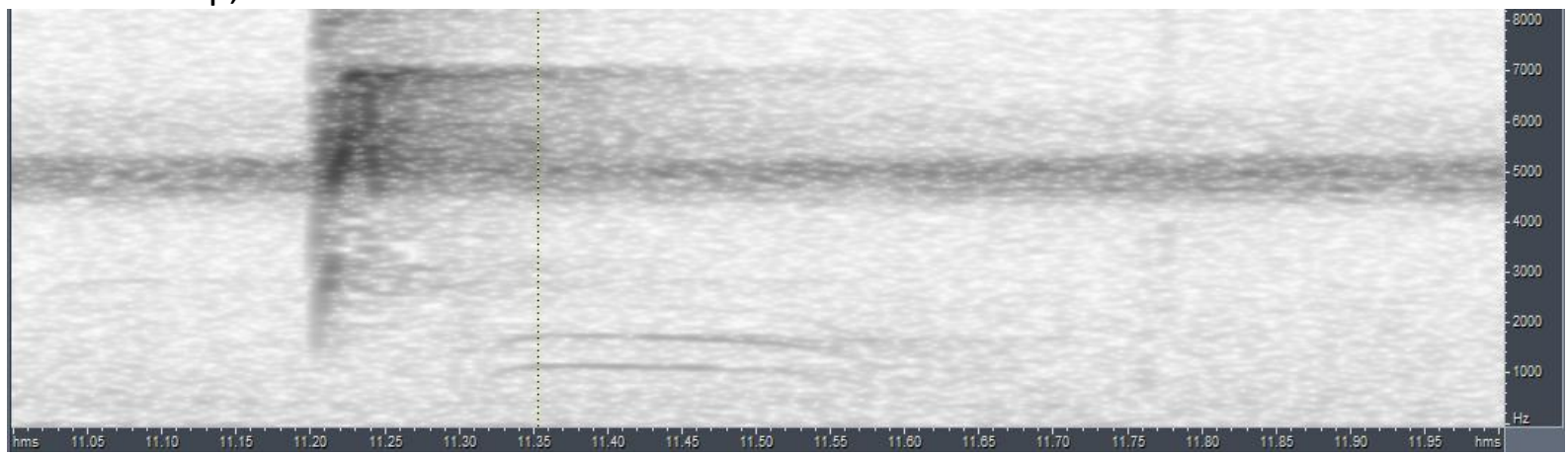

cearensis

Song typically is a fast rattle followed by a series of piping overslurred whistles which rise in pitch and increase in amplitude towards the end.

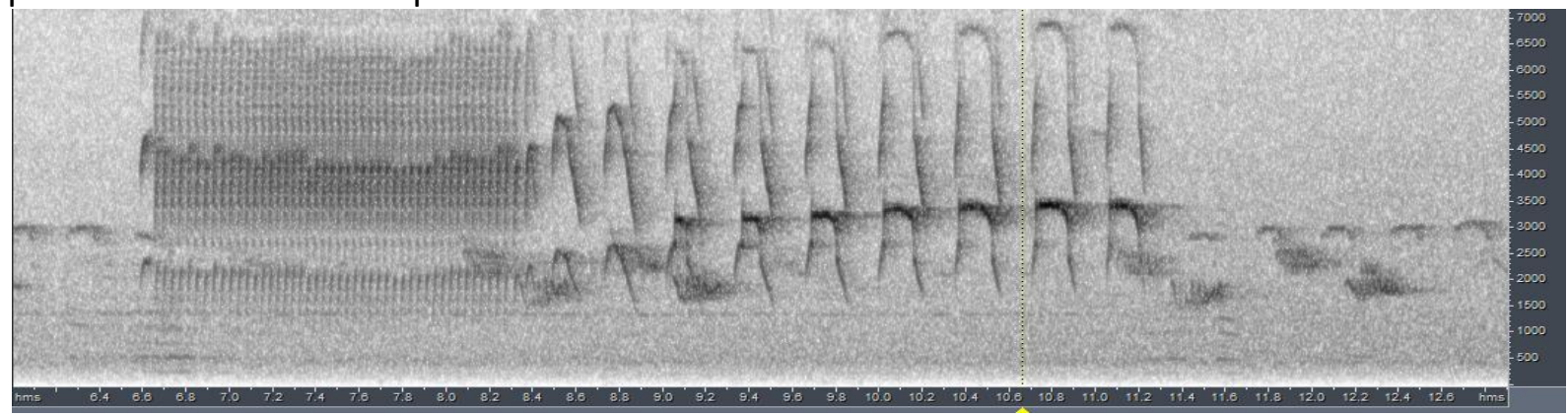

When excited, rattle and piping series are given intermittently (sonogram with different time scale):

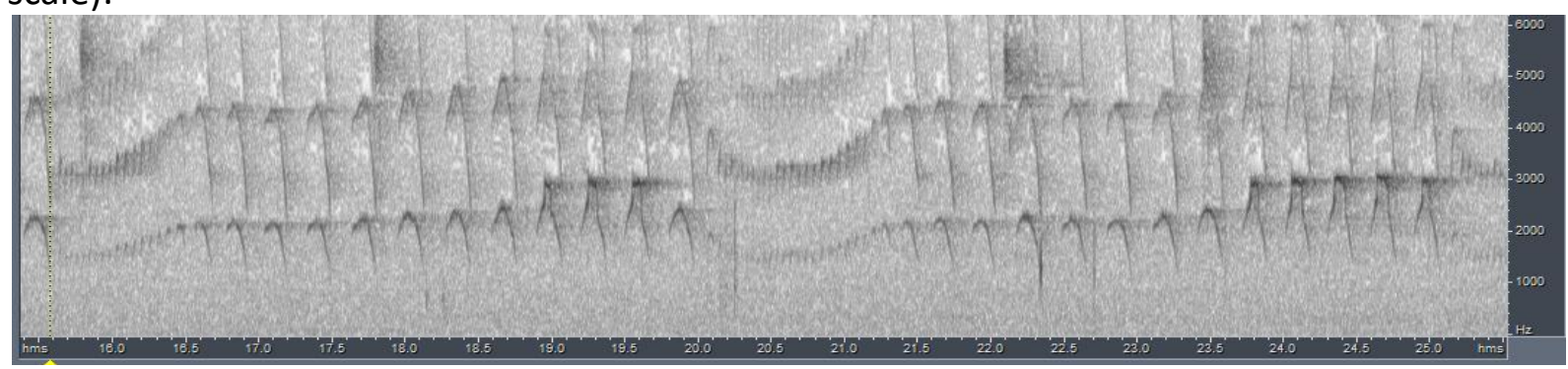

What could be called 'long call' or 'short song' is a descending series of notes:

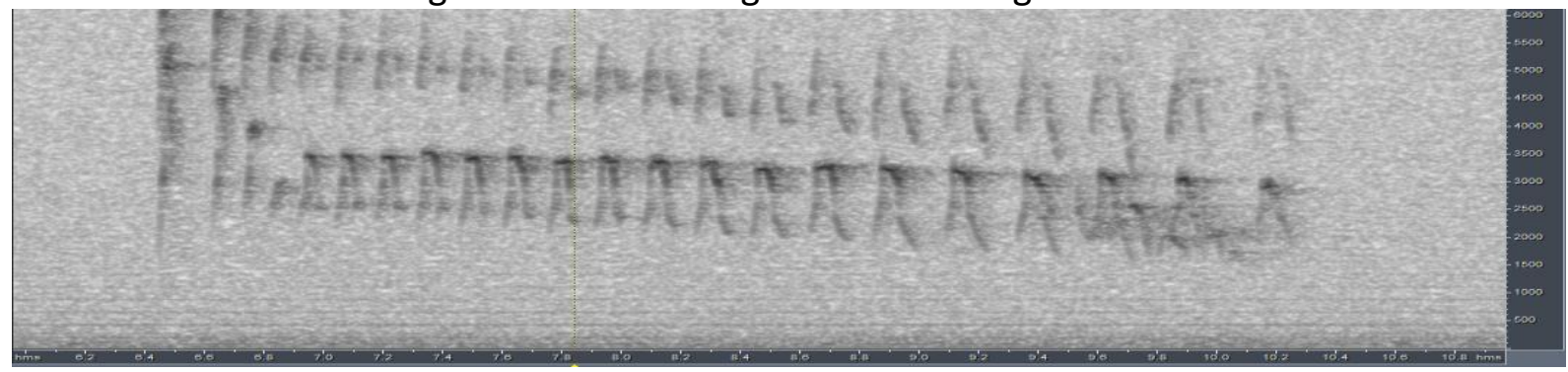



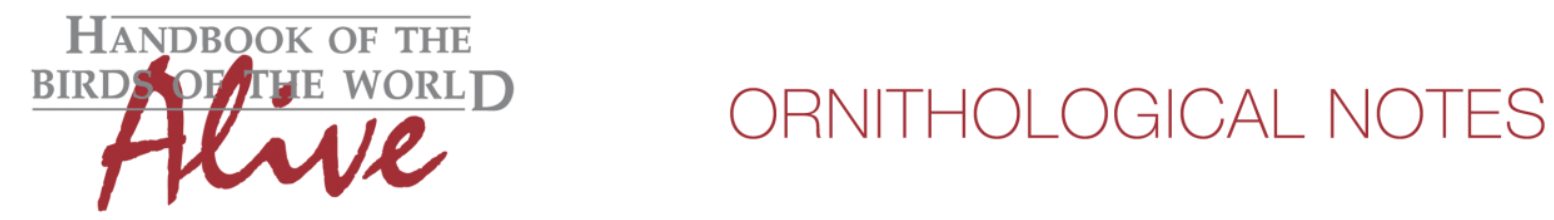

Call is a sharp, short note

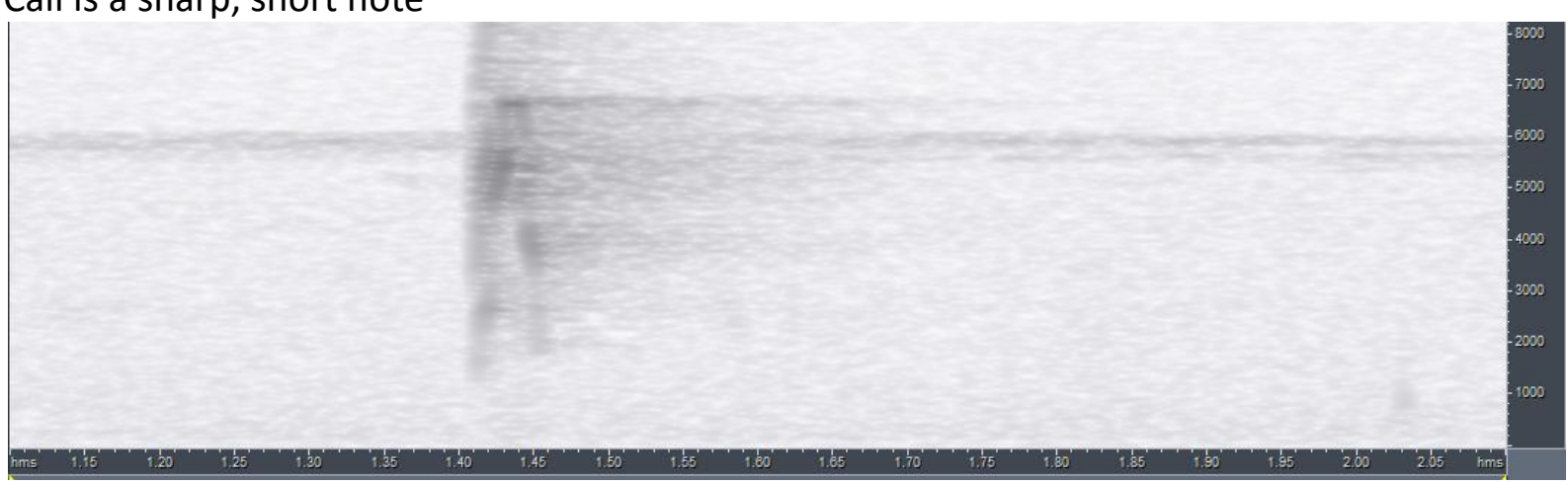

The main vocal difference clearly is the use of much longer notes in song of cearensis $(0.20$ $0.25 s)(n=8) v s .(0.04-0.08 s)$ for nominate $(n=8)$. If we would quantify this vocal difference according to Tobias criteria, this would lead to a score 3-4. Other basic parameters are similar.

Additionally, in comparable situations, the number of notes in cearensis is lower and has a rising end (vs. falling in scansor), but given the high variablity in song (presumably depending on excitement level, use of playback etc.) there is clearly some overlap. Score 1.

This leads to a total score for vocal difference of 4-5.

This note was finalized on 7th November 2015, using sound recordings available on-line at that moment. We would like to thank in particular the many sound recordists who placed their recordings for this species on XC and ML.

\section{References}

Tobias, J.A., Seddon, N., Spottiswoode, C.N., Pilgrim, J.D., Fishpool, L.D.C. \& Collar, N.J. (2010). Quantitative criteria for species delimitation. Ibis 152(4): 724-746.

\section{Recommended citation}

Boesman, P. (2016). Notes on the vocalizations of Rufous-breasted Leaftosser (Sclerurus scansor). HBW Alive Ornithological Note 77. In: Handbook of the Birds of the World Alive. Lynx Edicions, Barcelona. (retrieved from http://www.hbw.com/node/931965 on 14 July 2016). 